\title{
Mobile Learning Applications for Android und iOS for German Language Acquisition Based on Learning Analytics Measurements
}

\author{
https://doi.org/10.3991/ijai.v2i1.12317 \\ Markus Friedl, Markus Ebner ${ }^{(凶)}$, Martin Ebner \\ Graz University of Technology, Graz, Austria \\ markus.ebneretugraz.at
}

\begin{abstract}
The use of digital media is increasingly being promoted in school teaching. Since this aspect changes the interaction between teachers and pupils, this research is concerned with the development of a prototype of a mobile application for Android and iOS, in which different learning applications for language acquisition are offered on the basis of learning analytical measurements provided by experts in the field. By logging and collecting interactions of the user, it is possible to create a variety of statistical evaluations and thus respond to the needs and weaknesses of students. For the evaluation of the application, a user experience test was carried out, whereby the child-friendly operation of the application was tested. Due to the very positive feedback, the design was found to be good and can therefore be further developed.
\end{abstract}

Keywords—Learning Analytics, Language Acquisition, Mobile Learning Application, Digital Media in Teaching, Technology Enhanced Learning, Educational Data Mining

\section{Introduction}

In this day the use of digital media in school is steadily growing (Robin, 2008) and will play an ever-greater role in the future than it already is today. Instead of using classical learning materials, electronic aids such as computers are increasingly being used. Through the development of tablets and their widespread use, a new way of consuming digital media has been created. Due to their simple operation, most children of the youngest primary school age have already mastered the use of such devices, so that their use in the classroom is very obvious.

But s big problem is the changed communication between teacher and student. By solving tasks in digital form, they are usually corrected digitally, and the result is returned. This means that students often only see the result of their tasks without an oral explanation. It is also difficult to generate and provide individual tasks for classes or even individuals as platforms do not support this.

In order to counteract this aspect, a prototype of a mobile application for Android and iOS was developed in the course of this research. With the help of the application 
different exercise formats and different tasks will be offered to learn the German language based on Learning Analytics Measurements.

The exercises will be used by the IDeRBlog platform (Aspalter, Edtstadler, and Martich, 2017), which will be created and maintained by experts and teachers respectively. This platform provides an intelligent dictionary containing different data of each user, which will also be used in the app in the future.

Since all exercises and tasks are loaded by an API from an external server, the main focus of the app was a simple handling and comprehensible presentation of the contents. Particular attention was paid to child-friendly operation, as the main target group of the app are children of primary school age. In order to realize this aspect, a User Experience (UX) test with children from Austria was carried out. The task was that each child tried out all exercise formats and completed a short questionnaire after each exercise. In addition, a discussion was held about which things might be unclear or badly formulated and whether there were any suggestions for improvement. Since the feedback from the test was very positive and the children had a lot of fun practicing, the user-friendly design was confirmed and for this reason the prototype can be further developed in this way.

\section{Related Work}

\subsection{Digital media in teaching}

In general teaching can be explained as a process of interactions between teachers and their pupils. This process is supported by various activities by teachers with specific skills (Tulodziecki, Herzig, and Blömeke, 2017). The effect of digital media in teaching is influenced by different potential factors. These factors can be divided into following points (Herzig, 2014):

- The digital media and the content which is contained by the media

- Media offerings integrates different teaching processes

- The different persons which are involved in this process, in this area these are teachers and their pupils

According to (Herzig, 2014) the context of these factors there are four categories which serve to fulfil the factors. A digital media can have individual meanings, or an offer also can cause an interaction which have specific characteristics. These characteristics have more or less influence on the teaching process. Teachers usually have different areas of knowledge in which they are experts, and their expertise influences the way they teach and learn. Students also differ greatly in their knowledge, receptiveness to new knowledge and educational proximity. These factors show that the effect of digital media does not only depend on their content.

By using such media, the learning performance is to be increased in comparison to classical media, whereby an added value can be achieved. If, however, these media are too monotonous, this impairs the motivation of the learners and causes the opposite of a worse performance. The aim is to increase the learning performance and the 
success with unvarying effort or have a constant success in learning with less exertion (Kerres, 2002).

\subsection{Learning analytics}

With LA, large amounts of data are collected and evaluated so that the results can have a positive influence on the teaching process in the future. The terms Technology Enhanced Learning (TEL) and Educational Data Mining (EDM) are often associated with LA. LA can be seen as a subdivision of TEL and has been a new trend since it was mentioned a few years ago (Johnson, Adams, and Cummins, 2012). EDM deals with the storage of data and should answer the question of which data is important and meaningful in order to gain added value from LA (Duval, 2011).

Learning Analytics (LA) can be seen as a process with iterative steps. These steps can be divided into the following steps (Chatti et al., 2013):

- Data collection and pre-processing: In the first step, the data is collected and converted to a uniform format. The final result is influenced by the quality of the data.

- Analytics and action: With the aim of various techniques the collected data is analyzed and visualized. This step is aimed at increasing the effectiveness of learning.

- Post-processing: If the result obtained is not satisfactory, new data is collected in this step and the process starts again with the first step.

In addition, there are various drivers that can be used to better explain LA in the learning area. However, these drivers do not only apply to education, but are also used in many other areas and describe the complexity of LA. By the use of Virtual Learning Environment (VLE) systems large amounts of data, which is called big data, are generated. Therefore, it is important to create systems that can handle, analyze and process this amount of data within a reasonable time. It is also important that teachers receive feedback from online courses offered in order to evaluate and, where appropriate, improve the teaching process. Conversely, it is also important that students receive help from their teachers, even if they are not physically present. As a third major point, it is of crucial importance that this system is supported by politicians, as this process requires many resources and large investments.

\subsection{Mobile language learning applications}

Many mobile applications for language learning are offered. In relation to the developed prototypes, comparable applications were tested to get an overview and possible design suggestions. The focus was also on whether the applications could be used in schools.

What was immediately noticed during the research was that most applications offer very little content without payment. In addition, advertisements are often displayed, which makes their use in schools impossible. It should also be noted that the main target group of applications varies greatly. Many applications, which are designed for children, contain a lot of playful elements and animations, whereby the focus on 
learning often fades into the background and children are easily distracted. Other applications are mainly made for adults, but the design is often not very understandable for children.

Furthermore, it is often difficult that the mobile applications can be used in schools, because teachers rarely have access to the data of their students and can see or this functionality is not available at all.

\section{Research Design}

Many applications have been developed at the Graz University of Technology (TU Graz) in the past (Ebner, 2015). Each application must be evaluated by a field test to ensure that the application meets the specified requirements. Since all exercise formats and tasks are given by professors, the focus is on testing the design of the developed application. In order to evaluate the exercise format and its design, a questionnaire is completed after an exercise has been completed. These answers do not provide representative data in order to obtain a high-quality evaluation. Furthermore, the application must be tested by several children over a longer period of time in order to get better results.

In order to start the test, each child was provided with an iPad on which the application was already installed and ready for use. The children were then asked to select an exercise format one after the other and start an exercise. In order not to lose the overview, all children were asked to start the same exercise format and wait until everyone had finished the exercise. During the exercise, notes were written down to document the different reactions or possible problems that occurred. At the end of the exercise, each child fills in a questionnaire (Fig. 1), where they are asked to answer, whether the task was comprehensible, could be solved independently, whether the exercise was fun and whether the exercise would also like to be done at home. In order to make the evaluation understandable, smileys were used as a scale, whereby the laughing smiley means very good and the sad smiley not good. At the beginning of the test it could be noticed that the children felt that their performance was being evaluated and that the notes written refer to their solutions. Therefore, it was important to mention several times that only the application should be evaluated and that the children cannot do wrong. After a short period of familiarization, the children's nervousness subsided, and the application was tested with full concentration.

In addition to the questionnaire, the children in the group were asked if anything could be improved in the design or if anything was unclear. Then the same procedure was repeated with the next exercise format until all exercise formats were evaluated. 

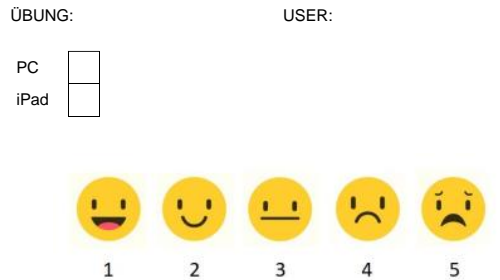

Ich wusste, was die Aufgabenstellung war.

Ich konnte die Aufgabe selber lösen.

Es hat mir Spaß gemacht zu üben.

Ich möchte die Übung auch zuhause machen.

Fig. 1. UX-Feedback questionnaire

\section{Prototype - IDeRBlog ii}

The IDeRBlog ii application is a native developed application for Android and iOS, which is designed for the use on tablets. The application is designed to support the learning of the German language based on LA measurements. In the application one has the possibility to select different exercise formats and to start tasks with different difficulty levels after the Login by means of username and password. The user login is required, since the application can currently only be used by members of the IDeRBlog platform. In addition, this platform provides a separate intelligent dictionary for each user, which will be used in the application in the future.

The application provides five different exercise formats as shown in Fig. 2, which contain any number of exercises in different difficulty levels. The first format in the upper right corner is called "Match" and in this exercise, pupils must assign a given word to different word categories. There are two basic types of the exercise of assigning a word. The first is by drag and drop a box to the correct categories. With the second type, a displayed word must be assigned to the correct categories and typed in correctly. After checking each task, the user receives feedback as to whether the task was solved correctly or incorrectly. If everything is correct, this is indicated by text and the exercise can be continued. If a mistake has been made, the user will be shown the correct solution as shown in Fig. 3. The user receives such feedback after each task has been solved, and any incorrect information is transferred to an external server for evaluation. 


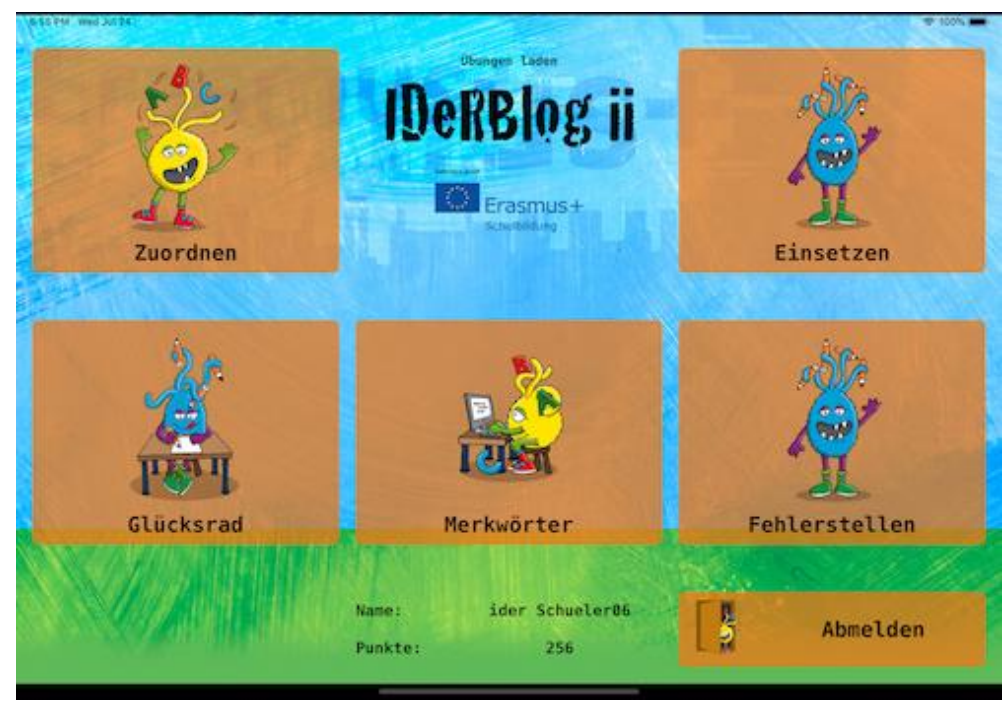

Fig. 2. Overview of the exercise formats

In the second exercise format (Fig. 2) in the lower left corner, which is called "Wheel of Fortune", pupils must type an auditioned word into an input field. The word can be auditioned as often as needed before it is entered. This exercise can be made more difficult by setting a timer that limits the time of input. If the word is entered correctly, it will be shown to the Student. Otherwise, the wrong input and the correct word will be displayed one below the other as feedback.

The third format with the title "Keywords" in the middle of the screen (Fig. 2) again has two basic configurations of the exercise. In the first configuration, a word is displayed which is divided into the individual letters or graphemes and the student must mark difficult places in the word. Once the word has disappeared, it must be entered correctly. In the second configuration, a timer limits the memorization of the word before it must be re-entered. The feedback after solving a task is identical to the previously mentioned feedback.

In the upper right corner (Fig. 2) is the "Insert" exercise format, where sentences with text gaps are displayed. The task is to fill in these gaps correctly so that the sentence makes sense. A description text can be displayed as an aid. When checking a sentence, correctly filled gaps are displayed in green and incorrect ones in red. The pupil cannot continue with a new sentence until all the gaps have been filled in correctly.

The last format in the lower right corner (Fig. 2) is called "Error locations". In this exercise, a sentence is displayed again, but this time it contains incorrect words. The pupil is asked to find and mark these wrong words. If an incorrect word is selected, an additional window will appear in which the reasons must be given by multiple choice selection for the correct spelling. 


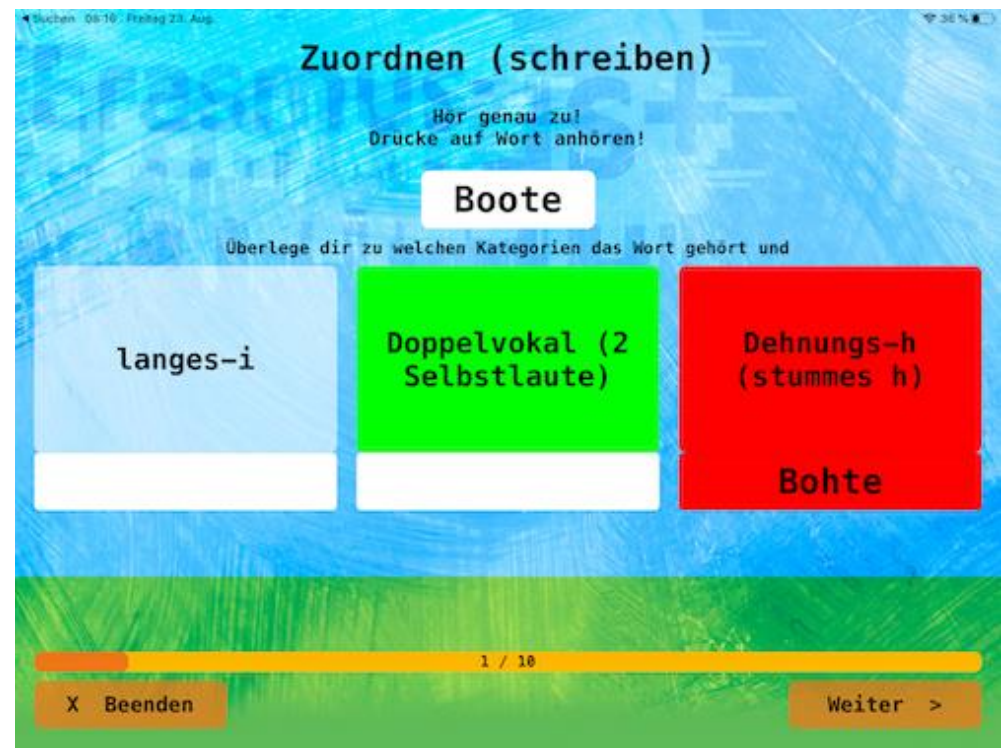

Fig. 3. Right answer in green with the wrong answer in red as feedback after evaluating a task.

By correctly solving tasks, the pupil has the opportunity to collect points, which are displayed in the overview (Fig. 2). These points can be used to unlock tasks within different exercise formats.

The same database is currently used as the exercise content for all users, which means there is currently no possibility to create individual exercises for a pupil.

As already mentioned, in the future the intelligent dictionary of the IDeRBlog platform will be integrated, so that every user can practice all individual words and sentences. This ensures that specific weaknesses can be practiced and eliminated.

\section{$5 \quad$ Field Study}

As a test group for the evaluation of the application, children from a third-grade elementary school in Austria should serve, which unfortunately did not come about due to technical problems or a lack of equipment. Therefore, a smaller group with five children aged between eight and eleven years was chosen as a replacement. The five children included two girls and three boys. Three iPads were used as test devices, on which the application was installed and ready for operation. Since the application can also be used offline, i.e. without an Internet connection, there is no need for an active Internet connection. Only the data sent to an external server and stored in a database could not be uploaded. Since not every child had an iPad, the children were divided into a group of three and a group of two children.

Before the test was started, the reason and the procedure for this evaluation were briefly explained. It was also mentioned several times that not the performance of the 
children, but the application should be evaluated, since the question often arose whether something happened if an exercise was not solved correctly.

After all the questions had been answered, the first group was asked to start the first exercise format.

It was immediately obvious that all children knew how to operate tablets from home or school and that the application was quickly understood.

After one exercise was completed, each child was asked to complete the questionnaire in Figure 1. In addition, questions were asked about the design and possible suggestions for improvement before the next exercise format was started.

The following questions were prepared:

- I had understood the assignment definition.

- I was able to solve the problem myself.

- I had fun to practice.

- I would also like to do the exercise at home.

The grading of the individual questions was done with the help of numerical values and smileys, where 1 or a laughing smiley means very good and 5 or a sad smiley does not mean good.

During the exercise, notes were written down again and again to document the behavior or possible problems which were taken into account in the further development of the application.

After about 40 minutes the first group was finished with all exercise formats and then the second group started the same procedure, which lasted about 40 minutes.

At the end a joint discussion was started again, which resulted in only positive feedback from the children. The question was even asked when the application would be available for everyone so that the children could continue to use it in the future.

A summary of all questions and the calculated mean value is shown in Table 1.

Table 1. Result of the evaluation questionnaire

\begin{tabular}{|l|c|c|c|c|}
\hline & $\begin{array}{c}\text { I had understood } \\
\text { the assignment } \\
\text { definition. }\end{array}$ & $\begin{array}{c}\text { I was able to solve } \\
\text { the problem } \\
\text { myself. }\end{array}$ & $\begin{array}{c}\text { I had fun to } \\
\text { practice. }\end{array}$ & $\begin{array}{c}\text { I would also like to } \\
\text { do the exercise at } \\
\text { home. }\end{array}$ \\
\hline $\begin{array}{l}\text { Error } \\
\text { locations }\end{array}$ & 1 & 1 & 1.2 & 1.2 \\
\hline Insert & 1.2 & 1 & 1.2 & 1.2 \\
\hline Keywords - Easy & 1 & 1 & 1 & 1 \\
\hline Keywords - Hard & 1 & 1 & 1 & 1 \\
\hline Match - Drag \& Drop & 1 & 1 & 1 & 1.2 \\
\hline Match - Write & 1 & 1 & 1 & 1 \\
\hline Wheel of Fortune & 1 & 1 & 1 & 1.5 \\
\hline Average & 1.03 & 1 & 1.06 & \\
\hline
\end{tabular}




\section{Conclusion}

This research deals with the use of a mobile application for Android and iOS to learn the German language based on LA measurement and to address primary school children in Austria as the main target group. A prototype of the application was developed, which was designed to be easy to use and child friendly. The design was evaluated with the help of a UX test of five children, which provided valuable feedback and was taken into account in the further development of the application. All exercise formats were specified by professors from the University College of Teacher Education Styria and together we developed the design and discussed how each exercise format could be implemented. The chosen design of the application and the user interface had to be as simply and understandable as possible, so children have no problems with the use of the application. The exercise data will be provided by the IDeRBlog platform, and the intelligent dictionary of this platform will also be used in the future. By this aspect it is then possible to make individual tasks available for each user together and these in the application, which are to go into the weaknesses of each individual purposefully and improve these.

Based on the very positive feedback, the decision can be made that the design concept of the first prototype can be described as well-chosen and it can be built on. However, it should be mentioned that the number of test users should be larger in order to get more representative data by the UX test.

\section{$7 \quad$ References}

[1] Aspalter, Christian, Edtstadler, Konstanze and Martich, Susanne (2017). "Recht/schreibdidaktische Überlegungen für den Einsatz der Internetplattform IDeRBlog" In: Open Online Journal for Research and Education (cit. on p. 1-7)

[2] Chatti, Mohamed Amine et al. (2013). "A reference model for learning

[3] Analytics." In: International Journal of Technology Enhanced Learning 4.5-6,

[4] pp. 318-331 (cit. on pp. 9-14)

[5] Duval, Erik (2011). "Attention please!: learning analytics for visualization and recommendation.” In: LAK 11, pp. 9-17 (cit. on p. 7). https://doi.org/10.1145/2090116.2090118

[6] Ebner, M. (2015). Mobile Learning and Mathematics. Foundations, Design, and Case Studies. Crompton, H., Traxler, J. (ed.). Routledge. New York and London. pp. 20-32

[7] Herzig, Bardo (2014). "Wie wirksam sind digitale Medien im Unterricht." In: Gütersloh: Bertelsmann Stiftung (cit. on p. 4)

[8] Kerres, Michael (2002). "Bunter, besser, billiger? Zum Mehrwert digitaler Medien in der Bildung (Why? On the Benefit of Digital Media in Educa- tion)." In: it-Information Technology 44.4, pp. 187-192 (cit. on p. 6). https://doi.org/10.1524/itit.2002.44.4.187

[9] Robin, Bernard R. (2008). "Digital Storytelling: A Powerful Technology Tool for the 21st Century Classroom." In: Theory into Practice 47.3, pp. 220-228. (cit. on p. 3). https://doi.org/10.1080/00405840802153916

[10] Tulodziecki, Gerhard, Bardo Herzig, and Sigrid Blömeke (2017). "Gestaltung von Unterricht: eine Einführung in die Didaktik.” In: 3311 (cit. on p.3) 


\section{Authors}

Markus Friedl studied Software Engineering and Management at Graz University of Technology, Graz, Austria.

Markus Ebner is currently working as a Researcher in the Department Educational Technology at Graz University of Technology. He deals with e-learning, mobile learning, technology enhanced learning and Open Educational Resources. His focus is on Learning Analytics at K-12 level. In addition, several publications in the area of Learning Analytics were published and workshops on the topic were held.

Martin Ebner is with the Department Educational Technology at Graz University of Technology, Graz, Austria. (E-mail: martin.ebner@tugraz.at). As head of the Department, he is responsible for all university wide e-learning activities. He holds an Assoc. Prof. on media informatics and works at the Institute of Interactive Systems and Data Science as senior researcher. For publications as well as further research activities, please visit: http://martinebner.at. Email: martin.ebner@tugraz.at

Article submitted 2019-11-11. Resubmitted 2020-01-07. Final acceptance 2020-01-14. Final version published as submitted by the authors. 